\title{
Research
}

\section{Comparison of traditional GP oral anticoagulation management with a nurse-led service involving near patient testing and computerized decision support}

Paul Barber, Susan Backhouse, Susan Timon, Clive Lawrence and David Seamark The Honiton Group Practice, The Surgery, Honiton, and Clive Lawrence, Explicata Ltd, Matford Business Park, Exeter, UK

\begin{abstract}
The use of oral anticoagulation therapy in primary care is increasing. We compared general practitioner (GP)-led oral anticoagulation monitoring with a nurse-led service involving near patient testing and computerized decision support (NPT-CDS). The nurse-led NPT-CDS service provided anticoagulation control equivalent to the traditional GP-led service, with identical mean international normalized ratio (INR) values and a nonsignificant trend towards improvement in all other parameters. Recording of indications for anticoagulation and target INR ranges were significantly improved using CDS software. For patients established on warfarin, the GP-led service was costed at $£ 56.88$ per patient per year, compared with $£ 63.76$ for the nurse-led NPTCDS service. Patients overwhelmingly preferred the NPT-CDS service for reasons of convenience, avoidance of phlebotomy and improved dosage instructions. Performance of the NPT-CDS service within the National External Quality Assurance Scheme (NEQAS) was satisfactory. In conclusion, nurse-led oral anticoagulation utilizing NPTCDS is an effective and acceptable alternative to traditional GP-led monitoring. The costs of an NPT-CDS service are higher, but need to be set against factors such as patient satisfaction and escalating GP workload.
\end{abstract}

Key words: cost analysis; primary care; quality control; warfarin

\section{Introduction}

Indications for oral anticoagulation of patients with high risk of thromboembolism are increasing (Sudlow et al., 1995; Sweeney et al., 1995), and there is debate as to where oral anticoagulation monitoring should take place (Hobbs and Fitzmaurice, 1997).

The advantages and disadvantages of near patient testing (NPT) machines for measurement of the international normalized ratio (INR) have been

Address for correspondence: Dr David Seamark, The Honiton Group Practice, The Surgery, Marlpits Road, Honiton EX14 2NY, UK.

Email: David.Seamark@gp-L83002.nhs.uk

(C)Arnold 2001 discussed elsewhere (Machin et al., 1996). The development of NPT machines for INR measurement and computerized decision support (CDS) software has enabled near patient testing and dosage adjustment of warfarin therapy to take place in primary care. Whether or not this transfer of clinical monitoring is desirable is unclear. Issues of safety, quality control, workload and cost are important factors in the debate surrounding the appropriate venue for oral anticoagulation monitoring (Sudlow et al., 1995; Hobbs, 1996; Anon., 1998).

This paper describes the practicalities of starting a nurse-led service using near patient testing and computerized decision support for oral anticoagulation monitoring in primary care. A cohort study 1463-4236(2001)PC060OA 
was adopted as a pragmatic solution to the existing clinical situation. A randomized controlled trial within the study population would not have been possible due to problems with patient acceptability and contamination between the two study groups. Limitations on the available resources meant that a cohort observational study was the most practical option.

\section{Setting and method}

The setting was a group practice situated in a market town serving a population of around 15000 patients. The practice has fully computerized medical records and specific screens for recording anticoagulation data. The GP-led service involved venous blood samples being taken in surgery, sent 17 miles to the district general hospital for INR determination, the results being sent back the following day, 11 GP partners making decisions with regard to warfarin dosage (without reference to dosage charts), and patients being telephoned to inform them of their results, instructions on the warfarin dosage and the date of the next test. The nurse-led service involved capillary blood sampling by means of a fingerprick device, immediate INR measurement using an NPT machine (Coagucheck) previously validated by the Medical Devices Agency (Medical Devices Agency, 1996) and in the surgery (Seamark et al., 1997), entry of the INR results into commercial software (INR Star) loaded on a personal computer, and printing out of the dosage instructions and the date of the next test. One printout was given to the patient (see Figure 1) and the next appointment was made straight away. The other printout (see Figure 2) was given to the patient's GP or deputy for approval the same day. The number of patients with an indication for anticoagulation and target INR range recorded was audited prior to and after the introduction of the nurse-led NPT-CDS method. Data were collected and analysed in 6-month periods according to previously published guidelines (Hobbs and Fitzmaurice, 1997) using an algorithm devised for this purpose (see Appendix 1). A transition period of 6 months at the start of the nurse-led service involved close supervision of the service by the lead research GP (D.S.). Weekly meetings with the practice nurse were held, and monthly analysis of the INR control for all patients was performed. The results from the transition period were analysed separately to those for the subsequent 6 months in order to highlight any problems with anticoagulation control that might arise. These meetings also provided opportunities for support for the nurse as she developed her extended role.

The NPT machine was subject to internal quality control and the UK National External Quality Assurance Scheme (NEQAS). The UK NEQAS is a robust national quality assurance scheme whereby a participating laboratory or practice regularly receives two anonymized samples. These are analysed and the results compared with the results obtained from the rest of the UK, giving an indication of the individual laboratory's performance. All GP-led and nurse-led study results were entered into the practice database and downloaded to Access files for analysis.

A record was kept of the number of times a doctor was asked to override the CDS result. Patients common to both anticoagulation monitoring methods were asked to complete a short structured questionnaire with space for comments at the end of the study period. The average percentage of the observation period within the range is quoted as a helpful measure of overall control, as the average percentage of INR tests within the range alone does not give any idea of time in the range. The average daily point prevalence of patients within the range gives a measure of the overall anticoagulation control of the whole cohort under study, and not just the individual patient.

\section{Results}

The results for all patients during the GP-led study period, the transition period to the NPT-CDS system and the nurse-led study period are shown in Table 1. The results for a set of patients common to all study periods are presented in Table 2.

The UK NEQAS results since the commencement of the near patient testing service are shown in Table 3. The results were 'within consensus' (15\% deviation of the median INR results) for 24 of $28(86 \%)$ samples. Delay in storage and analysis of the UK NEQAS samples occurred with two samples. Prior to the nurse-led service commencing, indications for anticoagulation and target INR ranges were specified for 78 of $144(54 \%)$ patients. 


\section{Honiton Medical Centre \\ Warfarin Dosage Service}

You should avoid taking aspirin whilst on warfarin. If you notice any undue bruising, nosebleeds or other abnormal bleeding, please contact your doctor on 0140441141 (or the nearest Casualty Department).

\begin{tabular}{|c|c|c|c|c|}
\hline Warfarin doses for: & \multicolumn{2}{|c|}{ Dawn Mist (111111) } & & \\
\hline Diagnosis: & \multicolumn{3}{|c|}{ Venous thromboembolic disease } & \\
\hline Target INR range: & \multicolumn{2}{|c|}{$2-2.5$} & \multirow{2}{*}{\multicolumn{2}{|c|}{ Warfarin dose: $3.0 \mathrm{mg} / \mathrm{day}$}} \\
\hline Today's INR: & \multicolumn{2}{|l|}{2.3} & & \\
\hline These doses are valid from: & \multicolumn{2}{|c|}{ 19-03-2001 } & \multicolumn{2}{|c|}{ Printed on: 19-03-2001 } \\
\hline \multirow[t]{2}{*}{ Previous results: } & Date & INR & Dose & Review \\
\hline & $\begin{array}{l}01-06-1998 \\
06-07-1998\end{array}$ & $\begin{array}{l}2.5 \\
2.4\end{array}$ & $\begin{array}{l}3.0 \\
3.0\end{array}$ & 8 \\
\hline
\end{tabular}

Please take your warfarin tablets each evening as indicated below.

\begin{tabular}{|lll|}
\hline Monday & $3 \mathrm{mg}$ & (one blue tablet) \\
Tuesday & $3 \mathrm{mg}$ & (one blue tablet) \\
(one blue tablet) & (one blue tablet) \\
Wednesday & $3 \mathrm{mg}$ & (one blue tablet) \\
Thursday & $3 \mathrm{mg}$ & (one blue tablet) \\
Friday & $3 \mathrm{mg}$ & (one blue tablet) \\
Saturday & $3 \mathrm{mg}$ & \\
Sunday & $3 \mathrm{mg}$ & \\
Please repeat your tablets as above for 10 weeks. & \\
Your next blood test is due on 28-05-2001. & \\
\hline
\end{tabular}

Your next appointment is on . . . . . . . . . . . . . . . . . . . . . . . . . . . . . . . . . . . with the Practice Nurse at Honiton Surgery. Please ring 0140141141 if you need to change this appointment or if you have any questions.

Authorized by $\mathrm{Dr} \ldots \ldots . \ldots . . . \ldots$

DAWN MIST

11 NOWHERE STREET

NOTOWN

EX10 4RF

Figure 1 Printout for patient of dosage instructions and date of next appointment.

Audit after the transition period indicated that all 161 patients $(100 \%)$ had indications and target ranges entered into their anticoagulation computer data.

A doctor was asked to override the CDS result on less than $2 \%$ of total INR determinations. Reasons for requesting a doctor to intervene included excessively elevated INR values, patients being initiated on warfarin, and patients requiring lowering of INR preoperatively.

In total, 89 of the 92 patients common to both study periods replied to the questionnaire. A total of 87 patients found the nurse-led service more convenient, 87 patients found written dosage

Primary Health Care Research and Development 2001; 2: 149-157 
152 Paul Barber, Susan Backhouse, Susan Timon, Clive Lawrence and David Seamark

\section{Honiton Medical Centre}

Warfarin doses for:

Dawn Mist (111111)

Diagnosis:

Venous thromboembolic disease

Target INR:

$2-2.5$

Starting date:

06-07-1998

Finish date:

Indef.

Suggested dose (mg/day):

3.0

Suggested review (weeks):

10

Printed On: 19-03-2001

\begin{tabular}{|llll|}
\hline Date of test & INR & $\begin{array}{l}\text { Dose } \\
\text { (mg) }\end{array}$ & $\begin{array}{l}\text { Review } \\
\text { (weeks) }\end{array}$ \\
\hline $01-06-1998$ & 2.5 & 3.0 & \\
$06-07-1998$ & 2.4 & 3.0 & 8 \\
$19-03-2001$ & 2.3 & 3.0 & 10 \\
\hline
\end{tabular}

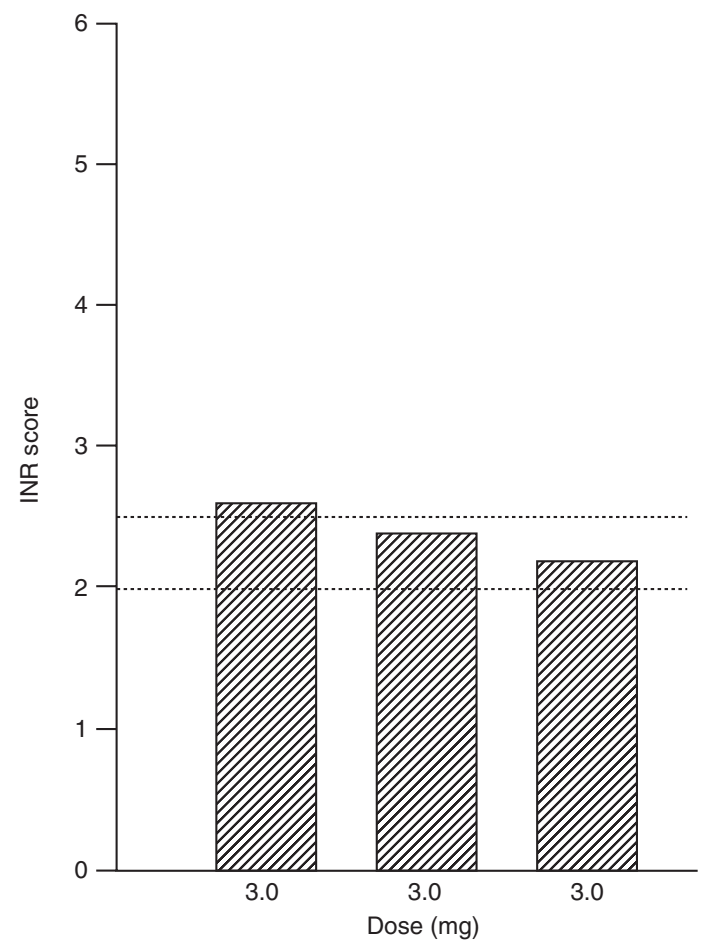

Figure 2 Printout for general practitioner of test results.

Primary Health Care Research and Development 2001; 2: 149-157 
Table 1 Results for all patients receiving oral anticoagulation

\begin{tabular}{|c|c|c|c|c|c|}
\hline & $\begin{array}{l}\text { GP-led service } \\
\text { A } \\
\text { (Jan-June 1997) }\end{array}$ & $\begin{array}{l}\text { Nurse-led service } \\
\text { Transition } \\
\text { (July-Dec 1998) }\end{array}$ & $\begin{array}{l}\text { Nurse-led service } \\
\text { B } \\
\text { (Jan-June 1999) }\end{array}$ & $t$-value & $P$-value \\
\hline Number of patients & 126 & 159 & 161 & & \\
\hline $\begin{array}{l}\text { Average \% observation period within } \\
\text { range }\end{array}$ & 57.2 & 52.5 & 60.0 & -0.77 & 0.44 \\
\hline Average $\%$ of INR tests within range & 50.2 & 49.8 & 53.5 & -0.91 & 0.36 \\
\hline $\begin{array}{l}\text { Average daily point prevalence of } \\
\text { patients within range } \%\end{array}$ & 55.2 & 58.0 & 60.4 & $*$ & * \\
\hline Mean INR (SE) & $2.6(0.05)$ & $2.6(0.04)$ & $2.6(0.04)$ & 0.56 & 0.58 \\
\hline $\begin{array}{l}\text { Average interval between tests } \\
\text { (days) }\end{array}$ & 29.3 & 32.9 & 31.1 & -0.80 & 0.42 \\
\hline
\end{tabular}

*t-test not applicable.

Table 2 Results for 92 patients common to all three periods

\begin{tabular}{|c|c|c|c|c|c|}
\hline & $\begin{array}{l}\text { GP-led service } \\
\text { A } \\
\text { (Jan-June 1997) }\end{array}$ & $\begin{array}{l}\text { Nurse-led service } \\
\text { Transition } \\
\text { (July-Dec 1998) }\end{array}$ & $\begin{array}{l}\text { Nurse-led service } \\
\text { B } \\
\text { (Jan-June 1999) }\end{array}$ & $t$-value & $P$-value \\
\hline $\begin{array}{l}\text { Average } \% \text { of observation period } \\
\text { within range }\end{array}$ & 60.6 & 53.4 & 62.7 & -0.54 & 0.59 \\
\hline Average $\%$ of INR tests within range & 53.2 & 52.2 & 56.0 & -0.64 & 0.52 \\
\hline $\begin{array}{l}\text { Average daily point prevalence of } \\
\text { patients within range } \%\end{array}$ & 61.3 & 57.0 & 63.7 & * & * \\
\hline Mean INR (SE) & $2.6(0.05)$ & $2.6(0.05)$ & $2.6(0.05)$ & -0.15 & 0.88 \\
\hline $\begin{array}{l}\text { Average interval between tests } \\
\text { (days) }\end{array}$ & 31.2 & 36.0 & 34.7 & -1.59 & 0.14 \\
\hline
\end{tabular}

*Paired $t$-test not applicable.

instructions helpful, 89 patients preferred fingerprick to venepuncture, and 86 patients rated the nurse-led service as better or very much better than the previous GP-led service. Content analysis of free text comments indicated that patients appreciated the speed and convenience of a one-step clinic, receiving immediate results and printed dosage instructions and avoiding phlebotomy.

The estimated costs of the two alternative anticoagulation services are shown in Table 4. Costing the two forms of management is not straightforward. The GP-led service was costed as a bulk contract with the local haematology laboratory. Estimated costs for INR determination are quoted at $£ 1.42$ per sample with total cost per sample at around $£ 4.50$. Based on the mean test interval (see
Table 1), the total cost per patient year can be estimated to be $£ 56.68$.

The nurse-led service can be costed rather more precisely using a volume of 1900 samples per annum. Capital outlay for the Coaguchek machine depreciated over three years, and nurse time costed at $\mathrm{D}$ grade, two clinics a week plus 1 hour of administration (a total of 8 hours). On the basis of a total cost per sample of around $£ 5.45$, and based on the mean test interval (see Table 1), the total cost per patient per year can be estimated to be $£ 63.96$.

This specific example considers patients who have been stabilized on warfarin. The cost of patient transport to the surgery has been ignored, as both services require a similar number of visits

Primary Health Care Research and Development 2001; 2: 149-157 
Table 3 Combined NEQAS results from August 1996 to November 1999

\begin{tabular}{|c|c|c|c|c|c|c|c|c|}
\hline $\begin{array}{l}\text { Survey } \\
\text { number }\end{array}$ & $\begin{array}{l}\text { INR } \\
\text { NPT1 }\end{array}$ & $\begin{array}{l}\text { INR } \\
\text { Median } 1\end{array}$ & $\begin{array}{l}\text { Percentage } \\
\text { deviation } 1\end{array}$ & & $\begin{array}{l}\text { INR } \\
\text { NPT2 }\end{array}$ & & $\begin{array}{l}\text { INR } \\
\text { Median } 2\end{array}$ & $\begin{array}{l}\text { Percentage } \\
\text { deviation } 2\end{array}$ \\
\hline 1 & 3.5 & 3.2 & 9.4 & 2.5 & & 2.4 & & 4.2 \\
\hline 2 & 2.6 & 2.55 & 2 & 5.6 & & 5.5 & & 1.8 \\
\hline 3 & 3.4 & 3.6 & -5.5 & 2.8 & & 2.55 & & 9.8 \\
\hline 4 & 3.1 & 2.9 & 6.9 & 3.4 & & 3.0 & & 13.3 \\
\hline 5 & 5.3 & 6.3 & -15.9 & 3.1 & & 3.0 & & 3.3 \\
\hline 6 & 2.5 & 3.4 & -26.5 & 1.9 & & 1.9 & & 0 \\
\hline 7 & 6.0 & 5.3 & 13.2 & 3.7 & & 3.55 & & 4.2 \\
\hline 8 & 3.2 & 3.4 & -5.9 & 3.7 & & 3.8 & & -2.6 \\
\hline 9 & 3.4 & 3.2 & 6.3 & 1.5 & & 1.4 & & 7.1 \\
\hline 10 & 3.8 & 3.6 & 5.6 & 3.6 & & 3.3 & & 0 \\
\hline $11^{*}$ & 3.5 & 2.8 & 25 & 4.5 & & 3.4 & & 32.4 \\
\hline 12 & 1.8 & 1.7 & 5.9 & 3.0 & & 2.8 & & 7.1 \\
\hline 13 & 3.9 & 3.7 & 5.4 & 1.6 & & 1.6 & & 0 \\
\hline 14 & 5.6 & 5.7 & -1.8 & 1.8 & & 1.8 & & 0 \\
\hline
\end{tabular}

*Delay in storage and analysis of NEQAS samples occurred.

Table 4 Estimated costs of the two alternative anticoagulation services

\begin{tabular}{lllr}
\hline GP-led service & $f$ & Nurse-led service & $f$ \\
\hline Laboratory cost & 1.42 & Coaguchek cost & 0.16 \\
Phlebotomy cost & 0.59 & Reagent strip & 2.87 \\
GP time (3 minutes) & 1.90 & NEQAS & 0.06 \\
Reception time & 0.59 & Internal quality control & 0.16 \\
Telephone call & 0.05 & Nurse time (D grade) & 1.83 \\
& & CDS software & 0.05 \\
Cost per test & & GP time (0.5 minutes) & 0.32 \\
Total cost per year & 4.55 & Cost per test & 5.45 \\
\end{tabular}

over a period of 1 year. Similarly, computer hardware costs are ignored, as both GP-led and nurseled services require personal computers.

\section{Discussion}

A recent systematic review (Delaney et al., 1999) concluded that there is little evidence to guide the expansion of the use of near patient testing in primary care. However, the reality is that near patient testing for oral anticoagulation monitoring is increasing in an ad hoc manner (personal observation) without evaluation. This paper seeks to provide some insight into the practicalities, costs and possible benefits of the introduction of NPT-
CDS methodology. It is the first study we are aware of that has compared traditional GP-led care with nurse-led care employing NPT-CDS methodology, using patients as their own controls.

The nurse-led NPT-CDS service provides anticoagulation control equivalent to the traditional GP-led service, with identical mean INR values and a nonsignificant trend towards improvement in all other parameters. Even during the 6-month transition period to the NPT-CDS service, control was maintained despite the perceptions of GPs that patients were attending more frequently and that control was deteriorating. Recording of indications for anticoagulation and target INR ranges were both vastly improved by adoption of the CDS software. 
The transition from a GP-led service to a nurse-led one did produce a degree of uncertainty among GPs, with the perception that patients were being recalled more frequently for blood tests with the nurse-led service. This perception was in fact only true for a small percentage of patients, whilst the analysis of the average interval between tests (see Tables 1 and 2) showed a slight increase in testing intervals with adoption of the nurse-led service. The CDS software permits swift analysis of the testing frequencies for the patient population, and this data provides useful reassurance for the primary health care team at a time of transition. The development of nurse autonomy in providing a service traditionally managed by clinicians (either in hospital-based clinics or in general practice) requires careful management. We have found it important to have one lead GP who can provide reassurance, a second opinion and educational input. The development of nurse autonomy has led to increased confidence in the nurse's clinical decision making (e.g., when to request a doctor's opinion), confidence in educating patients who have erratic control, and ability to detect clinical problems not necessarily related to the patient's anticoagulation control. For the introduction of the nurse-led service it was felt to be important to concentrate expertise in the hands of one nurse with an interest in anticoagulation control.

Now that the service has been established and evaluated, a second practice nurse has been trained to run the service during periods of annual leave, sickness, etc.

On the basis of our experience, nurturing a shift in role for a nurse in a supportive environment is just as important as training a nurse to operate a machine and be technically competent.

The effect of introducing a nurse-led NPT-CDS service seems to have been entirely positive from the patient's viewpoint. In order to reduce artefactual responses, the questionnaire was only administered to patients who had experienced both the GPled and nurse-led service at the end of 12 months of the nurse-led service.

Patients preferred the nurse-led service, appreciating the immediacy of the results, fingerprick testing and written dosage instructions (see Figure 1). GPs appreciated the reduction in workload and not having to decide on warfarin dosages, especially for patients whom they did not know. They found the INR graphs and the warfarin dosage charts produced by the commercial software helpful for reviewing patient control (see Figure 2).

Quality control has been carefully monitored using both internal and external controls. The UK NEQAS provides valuable insights into how the practice is performing compared with other near patient testing centres, and a result outwith the consensus limits is a strong incentive to investigate possible reasons for the deviation.

The costs of the two services are difficult to compare, although it would appear that nurse-led NPT-CDS management is more costly than traditional management. The cost needs to be evaluated in the light of patient acceptability, possible improvement in control, and decreased frequency of testing and reduction in GP workload. It was not possible to determine whether nurse-led NPTCDS management led to improved safety in this study, as the incidence of severe complications of over- or under-anticoagulation was very low in the study population. This aspect would require a larger multicentred trial to establish whether NPTCDS management is safer.

A pharmacist-led NPT service, not using CDS, was preferred by patients, but the results presented did not use standard parameters, making comparison difficult (Macgregor et al., 1996). One study compared primary care management with traditional hospital care (Fitzmaurice et al., 1997), and subsequently analysed data from one practice involving 29 patients over one year (Fitzmaurice et al., 1998). The results obtained from these studies are comparable with the findings of this study, but failed to quote all previously recommended parameters and did not use patients as their own controls.

In conclusion, the adoption of a nurse-led service for oral anticoagulation using NPT-CDS is effective and popular with patients. The costs of an NPT-CDS service are higher but need to be seen in the light of patient satisfaction and escalating GP workload, which might represent an obstacle to further implementation of oral anticoagulation therapy in primary care (Sudlow et al., 1995). In planning the development of such services, issues of service costs, clinical responsibility and quality control need to be considered carefully. 


\section{Acknowledgements}

P.B. and D.S. designed and supervised the study, S.B. collected and verified the data, C.L. and S.T. prepared and analysed the data and D.S. wrote the paper and will act as guarantor for it.

This study was funded by the North and East Devon Health Authority Trust Fund. The Honiton Group Practice receives research infrastructure support from the NHS Executive Research and Development Directorate.

\section{References}

Anon. 1998: Guidelines on oral anticoagulation, 3rd edn. British Journal of Haematology 101, 374-87.

Delaney, B.C., Hyde, C.J., McManus, R.J., Wilson, S., Fitzmaurice, D.A., Jowett, S., Tobias, R., Thorpe, G.H. and Hobbs, F.D.R. 1999: Systematic review of near patient test evaluations in primary care. British Medical Journal 319, 824-27.

Fitzmaurice, D.A., Hobbs, F.D.R., Murray, E.T., Gilbert, M. and Rose, P.E. 1997: A randomised controlled trial comparing primary care oral anticoagulant management utilising computerised decision support (DSS) and near patient testing (NPT) versus routine care: final results. British Journal of Haematology 97, S79.

Fitzmaurice, D.A., Hobbs, F.D.R. and Murray, E.T. 1998: Primary care anticoagulant management using computerised decision support and near patient international normalised ratio (INR) testing: routine data from a practice nurse-led clinic. Family Practice 15, 144-46.

Hobbs, R. 1996: Near patient testing in primary care. British Medical Journal 312, 263-64.

Hobbs, F.D.R. and Fitzmaurice, D.A. 1997: Where should oral anticoagulation monitoring take place? British Journal of General Practice 47, 479-98.

Macgregor, S.H., Hamley, J.G., Dunbar, J.A., Dodd, T.R.P. and Cromarty, J.A. 1996: Evaluation of a primary care anticoagulant clinic managed by a pharmacist. British Medical Journal 312, 560.
Machin, S.J., Mackie, I.J., Chitolie, A. and Lawrie, A.J. 1996: Near patient testing (NPT) in haemostasis - a synoptic review. Clinical and Laboratory Haematology 18, 69-74.

Medical Devices Agency 1996: Evaluation Report: Boehringer Mannheim Coaguchek ${ }^{\circledR}$ coagulation monitor. London: HMSO.

Seamark, D.A., Backhouse, S., Barber, P., Hichens, J., Lee, R. and Powell, R. 1997: Validation of current practice and a near patient testing method for oral-anticoagulant control in general practice. Journal of the Royal Society of Medicine 90, 657-60.

Sudlow, C.M., Rodgers, H., Kenny, R.A. and Thomson, R.G. 1995: Service provision and use of anticoagulants in atrial fibrillation. British Medical Journal 311, 558-61.

Sweeney, K.G., Gray, D.P., Steele, R. and Evans, P. 1995: Use of warfarin in non-rheumatic atrial fibrillation: a commentary from general practice. British Journal of General Practice 45, $153-58$.

\section{Appendix 1 Algorithm}

In order to carry out the analyses, the following quantities were defined.

$(\mathrm{P})=$ period of observation $($ of a patient $)=$ date of final examination - date of initial examination.

$(\mathrm{T})=$ total number of examinations during a period of observation.

To determine the out-of-range period for each patient, within their observation period $(\mathrm{P})$, a number of assumptions were made.

Let Figure 3 represent a fragment of a patient's observation period, at certain points within which examinations take place.

At each examination (E), a patient is assessed to be either in range or out of range (i.e., below or above his or her designated target range).

$\mathrm{A}$ is half the time interval (in days) from the current examination $\mathrm{E} *$ back to the previous exam-

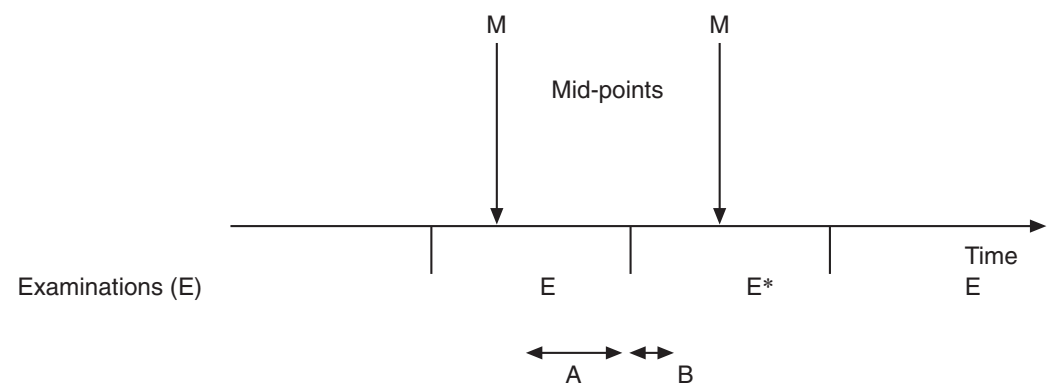

Figure 3

Primary Health Care Research and Development 2001; 2: 149-157 
ination. If there is no previous examination, $\mathrm{A}$ is made equal to 10.5 days.

$\mathrm{B}$ is half the time interval (in days) from the current examination $\mathrm{E} *$ to the next examination, unless at $\mathrm{E} *$ the test result is out of range, in which case $\mathrm{B}$ is made equal to the minimum of [3.5 days, half the time interval to the next examination], the reasoning for this being that when an out-of-range result occurs, treatment is changed in a way that is designed to bring the patient's reading into range.

Using this approach we are able to break up the observation period $(\mathrm{P})$ into a sequence of in-range and (if there are any) out-of-range periods. Let
(PO) denote the total period out of range and (TO) denote the total number of tests out of range in the observation period for each patient. For calculation purposes we define the following:

percentage period out of range $=\frac{100 *(P O)}{P}$;

percentage of tests out of range $=\frac{100 *(T O)}{T}$;

and Int days $=\frac{P}{T}$, the average number of days between tests. 